\title{
MANIFESTAÇÕES PATOLÓGICAS NA ESTRUTURA DE UM TELHADO: ESTUDO DE CASO $^{1}$
}

Amanda Fernandes Pereira da Silva, Marcos Alécio Campos da Silva, Diego Silva Ferreira, Hildegard Elias Barbosa Barros, Lilian Vitória Viana Lima Santos, Elias Antonio de Sousa Gomes, Natanael da Silva Lima² Centro Universitário Santo Agostinho

\begin{abstract}
RESUMO
Uma frequente causa de danos em estruturas de madeira é a introdução de esforços inadequados devidos a algumas alterações intencionais como, por exemplo, adaptações e mudanças de áreas, ou podem ser alterações acidentais como cedência de apoios. Assim, este trabalho tem por intuito realizar uma análise de um telhado de madeira de um edifício residencial localizado em Teresina-PI que apresenta patologias de origem estrutural de modo a servir como embasamento para pesquisas futuras e ser referência ao tema. Baseando-se em literaturas e com registro de imagens feitas in loco, foi realizado um levantamento de dados que puderam auxiliar-nos a entender as possíveis causas dos problemas detectados e formular sugestões que possam resolvê-los. Constatou-se que a estrutura mostrou-se instável com deslocamentos e flechas observáveis e apresentando algumas manchas que modificaram a coloração da madeira. Assim, é proposto que haja no desenvolvimento da obra ou de reabilitação um planejamento de concepção que deve ser seguido de modo a conferir durabilidade para, isto posto, vir a ter manutenção e reparo das estruturas à base de madeira, já que este material possui especificações muito próprias.
\end{abstract}

Palavras-Chave: Patologia. Edifício. Telhado. Estruturas de madeira.

\section{INTRODUÇÃO}

Como a madeira é um material anisotrópico, ou seja, com propriedades mecânicas que dependem da disposição de suas fibras, é preciso conhecer as variabilidades naturais que este material possui que está diretamente ligado ao tipo de árvore na qual a madeira é extraída e ao seu desempenho em contato com o ambiente. Quanto a isso e sabendo que ela é de origem natural, as

\footnotetext{
${ }^{1}$ Trabalho apresentado no Congresso Brasileiro Ciência e Sociedade (CBCS 2019), promovido pelo Centro Universitário Santo Agostinho, de 03 a 05 de outubro de 2019, em Teresina-PI.

${ }^{2}$ Graduanda em Bacharelado em Engenharia Civil, Centro Universitário Santo Agostinho, amandafeernandes09@gmail.com; Graduando em Bacharelado em Engenharia Civil, Centro Universitário Santo Agostinho, alecio_campos@ hotmail.com; Engenheiro Civil, Centro Universitário Santo Agostinho, diegof.engenheiro@gmail.com; Engenheiro Civil, Centro Universitário Santo Agostinho, hildegardebbarros@gmail.com; Graduanda em Bacharelado em Engenharia Civil, Centro Universitário Santo Agostinho, lilianviana7@ hotmail.com; Graduando em Bacharelado em Engenharia Civil, Centro Universitário Santo Agostinho, gomeselias075@gmail.com; Graduando em Bacharelado em Engenharia Civil, Centro Universitário Santo Agostinho, 15natan11@gmail.com. 
ANAIS CBCS 2019 | 3 a 5 de outubro de 2019 | Centro Universitário Santo Agostinho - Teresina - P

suas características são bastante particulares acarretando em problemas construtivos que requer análises amplas e específicas.

O comportamento mecânico da madeira leva em conta a variabilidade que ocorre entre as espécies (genética), presente na mesma espécie (genética e fatores do meio ambiente) e a que se origina no interior de cada árvore (fatores do meio ambiente que contribuem para o crescimento específico da árvore). Em consequência disso, a madeira se torna um material com heterogeneidade significativa, mas que possui propriedades vantajosas para o seu uso na construção civil tais como durabilidade e solidez que são essenciais em estruturas resistentes que necessitam de um desempenho adequado.

Convêm esclarecer que as principais causas da deterioração da madeira são os agentes abióticos (físicos, químicos, atmosféricos, devido ao fogo, etc.) e oriundos de anomalias estruturais; e os agentes bióticos (bactérias, fungos, insetos, perfumadores marinhos, etc.) (BRITO, 2014). Por isso, é essencial que se verifique a qualidade da madeira levando em consideração a utilização que se pretende.

Em face ao exposto, este trabalho tem por objetivo realizar um estudo de caso de um telhado de madeira em um edifício residencial localizado em Teresina (PI), que apresenta algumas patologias de origem estrutural e algumas manchas que alteraram a coloração da madeira onde se puderam determinar as possíveis causas que originaram tais problemas assim como elaborar algumas sugestões para solucioná-los.

\section{METODOLOGIA}

A organização do trabalho baseou-se em duas etapas. A primeira etapa consiste em apresentar uma breve explicação de como as patologias em construções de madeira originam-se englobando definições de modo genérico, dos agentes causadores dessas patologias dando uma ênfase maior aos agentes físicos de origem estrutural, já que há a hipótese desses agentes terem sido os maiores causadores de algumas das patologias do telhado de madeira do estudo de caso, e de algumas técnicas de resolução, baseando-se em literaturas, para servir como auxílio para o 


\section{CONGQEESSOCIENCIAESOCIEDADE

ANAIS CBCS 2019 | 3 a 5 de outubro de 2019 | Centro Universitário Santo Agostinho - Teresina - PI

levantamento de dados que foi realizado do estudo de caso. E a segunda etapa, apresentar a análise completa feita do estudo de caso.

\section{PATOLOGIAS EM CONSTRUÇÕES DE MADEIRA}

\section{CONCEITO}

Patologias das Estruturas é um tema do âmbito da Engenharia Civil que abrange o estudo das origens, como se manifestam, efeitos e mecanismos de ocorrência das falhas dos sistemas estruturais e/ou de deterioração dos elementos estruturais (SOUZA; RIPPER, 1998). Porém, deve-se também englobar no que diz respeito à concepção estrutural e a de projeto em termos de capacidade de desempenho futuro com a necessidade de reabilitar e manter seguras e estáveis às estruturas existentes, não se restringindo a apenas um conhecimento e processo de identificação das patologias, mas também como uma percepção do próprio Engenheiro Civil do comportamento estrutural ao longo do tempo, desde a concepção até a manutenção da estrutura (SOUZA; RIPPER, 1998).

\section{AGENTES DE DETERIORAÇÃO DA MADEIRA}

Como citado anteriormente, as patologias das construções em madeira podem ser ocasionadas por alterações físicas ou químicas nos elementos de madeira (agentes abióticos) e degradação das suas propriedades, perda de aptidão, por uso inadequado ou novas exigências de seu desempenho; por deterioração em ambientes que favoreçam o desenvolvimento dos seus predadores tais como fungos, bactérias, insetos, etc. (agentes bióticos).

\section{AGENTES ABIÓTICOS - AGENTES FÍSICOS}

A modificação das condições iniciais (adaptações, alteração de áreas) e/ou mudanças na utilização (cedência de apoios, acidentais) em estruturas de madeira geram esforços inadequados que tem sido uma frequente causa de problemas construtivos e danos (CRUZ, 2001). 
ANAIS CBCS 2019 | 3 a 5 de outubro de 2019 | Centro Universitário Santo Agostinho - Teresina - PI

As patologias devido a agentes abióticos (físicos) comprometem o funcionamento estrutural em um telhado de madeira, por exemplo, causando instabilidade, remoção de elementos estruturais, fraturas incipientes, movimentação de ligações e distorções, deformações, deslocamentos e flechas e defeitos naturais da madeira (CRUZ, 2001).

\section{PATOLOGIAS DE ORIGEM ESTRUTURAL (AGENTES FÍSICOS)}

Utilização inadequada, ações de sobrecargas acidentais, falta de manutenção ou alterações intencionais no uso e/ou ampliações na estrutura original, resultado de muitos anos de serviço, podem acarretar problemas desastrosos onde poderão surgir defeitos devidos a falhas de concepção e em projetos estruturais, uma execução inadequada das ligações. Ainda falhas na escolha e na seleção de materiais durante o serviço de execução e sem os cuidados necessários, além de casos de falhas em manutenções corretivas [(MACHADO et al., 2009); (CRUZ, 2016); (COSTA, 2009); (DRIEMEYER, 2009); (BRANCO et al., 2012)]. São os fatores mais relevantes que provocam a aparição de patologias em estruturas de madeira. Na sequência serão descritos de maneira sucinta alguns dos principais tipos de deteriorações em estruturas de madeira oriundas de agentes físicos.

- Remoção de elementos estruturais: é muito comum encontrar estruturas de coberturas de madeira danificadas pela remoção de suas partes para instalação de utilidades, em reformas, ou decorrentes de manutenções com concepções incorretas, além de outras atividades de carpintaria [(MACHADO et al., 2009); (CRUZ, 2016); (BRANCO et al., 2012); (BRITO; CALIL, 2012)]. Assim como cortes ou remoções de vigas ou peças de elementos estruturais tracionados. A redução da seção transversal de vigas e transversinas também podem diminuir sua capacidade resistente (CALIL, 2006).

- As deformações, deslocamentos e flechas: podem indicar excessivo carregamento, que necessita de correção com manutenções adequadas [(MACHADO et al., 2009); (BRANCO et al., 2012); (CALIL, 2006); (ARRIAGA et al., 2002); (ALVIM, et al., 2011)]. Em estruturas antigas o deslocamento pode ser oriundo do efeito da fluência ou secagem a partir de uma condição de madeira verde. Isso pode ou não, conduzir a problemas estruturais (CALIL, 2006). 


\section{CONGQEESSOCIENCIAESOCIEDADE

ANAIS CBCS 2019 | 3 a 5 de outubro de 2019 | Centro Universitário Santo Agostinho - Teresina - PI

- Instabilidade: as manifestações patológicas das estruturas de madeira, muitas vezes podem estar relacionadas com as falhas de concepção, de análise, de construção e de utilização. A instabilidade geralmente pode ser observada em deslocamentos laterais excessivos ou em movimento de pórtico, usualmente causado por danos, corte ou falta de barras de contraventamento (CALIL, 2006). Os tipos de instabilidade mais comuns em estruturas de madeira são: instabilidade local (instabilidade lateral em vigas, e flambagem em pilares) e instabilidade global da estrutura.

\section{AGENTES QUÍMICOS}

O contato da estrutura de madeira com produtos químicos. A seguir tem alguns exemplos (RITTER; MORRELL, 1990).

- Bases fortes que atacam a hemicelulose e lignina, deixando a madeira com coloração esbranquiçada;

- Ácidos fortes atacam a celulose e hemicelulose, ocasionando perda de peso e resistência;

Referindo-se ao efeito da corrosão na madeira, as degradações surgem em ambientes marinhos e áreas industriais. Quando a umidade na madeira reage com o ferro de uma ligação metálica é que caracteriza o aparecimento da corrosão (BRITO, 2014).

\section{AGENTES ATMOSFÉRICOS}

Provocam alterações de cor e textura alterando a parte estética da madeira podendo ficar mais clara ou escura devido ao intemperismo. Em ambientes externos, é a ação da chuva, da radiação solar e ciclos de secagem e umidificação que degradam a madeira.

\section{AGENTES BIÓTICOS}

As bactérias atacam a madeira quando esta se encontra enterrada ou submergida fazendo com ela fique "perfurada" e tenha sua higroscopicidade aumentada. 
ANAIS CBCS 2019 | 3 a 5 de outubro de 2019 | Centro Universitário Santo Agostinho - Teresina - P

Já os fungos (basidiomicetos e ascomicetos), decompõem a madeira de tal forma a causar o seu apodrecimento. E podem se proliferar devido a manchas de umidade por infiltrações detectadas visualmente pela variação na coloração da madeira.

E os perfuradores marinhos, os organismos marinhos que causam danos à madeira podem ser divididos em duas categorias: moluscos e crustáceos. Os Teredos são os mais conhecidos, entre os moluscos. A Limnoia é o crustáceo xilófago mais difundido no mundo (MENDES; ALVES, 1988).

\section{ALGUMAS TÉCNICAS DE REPARAÇÃO}

O processo de recuperação subdivide em duas categorias (RITTER; MORRELL, 1990):

1. A degradação existente não afeta o desempenho estrutural da madeira. As possíveis técnicas utilizadas são: fumigação, injeção, aspersão e pincelamento;

2. Envolve a restauração da capacidade de carga requerida para a estrutura de madeira, bem como das condições iniciais. As técnicas mais utilizadas para se fazer estas recuperações são: método tradicional - a estrutura de madeira é reforçada com novas peças, de dimensões e tamanhos semelhantes aos originais; método mecânico - os reparos estruturais são feitos utilizando conectores metálicos e o método adesivo - são utilizadas variações de resinas epóxi combinadas com peças metálicas, para realizar os reforços (ETTEM; ROBINSON, 1991).

\section{ESTUDO DE CASO}

O estudo de caso refere-se a um telhado de madeira de um edifício residencial com 2 pavimentos localizado em Teresina (PI) que apresenta diversas patologias. Inicialmente foi realizado um levantamento de dados através de entrevistas informais com os proprietários do edifício sobre as condições de serviço em que foi executado o telhado para, assim, facilitar o entendimento quanto às possíveis causas que podem ter acarretado o surgimento das patologias encontradas. De acordo com a entrevista obtivemos as seguintes informações: O telhado é de madeira Pau D’arco (ver Figura 1). A escolha e seleção do material foram devido a sua utilização em estruturas de telhado em madeira aparente com grande resistência a ataques de cupins, às intempéries climáticas e não por 


\section{cONGERESOC CIENCIAESOCIEDADE Inovação, Diversidadie e Sustentahilitidade}

ANAIS CBCS 2019 | 3 a 5 de outubro de 2019 | Centro Universitário Santo Agostinho - Teresina - PI

questão estética, devido a sua exposição; Não houve processo de manutenção desde concluído a sua execução, execução esta feita em 1985; A viga possui dimensão de 7x14. Ela possui uma espessura inferior ao que foi previsto em projeto para a distância na qual ela é usada, por isso está recebendo uma carga inadequada; Nos apoios laterais da viga que apresenta as patologias parte do reboco desprendeu (ver Figura 2); Não ocorreu a remoção de nenhum elemento estrutural; Presença de trama (ripas, caibros e terças). Mas há encaixes mal feitos de telhas apoiadas nas ripas que geram algumas goteiras em períodos chuvosos como se verifica na Figura 3.

FIGURA 1. Visão geral do telhado de madeira Pau D'arco

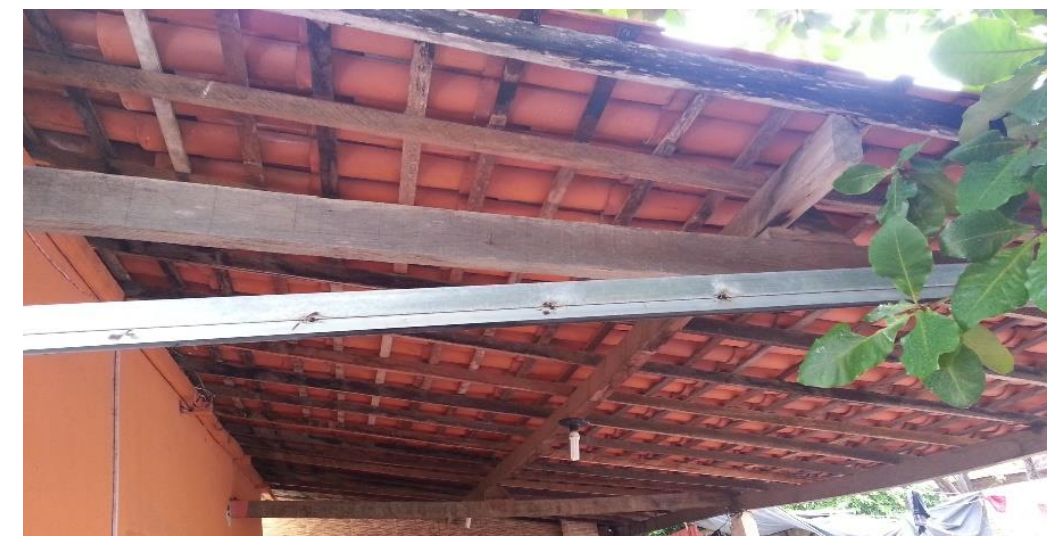

Fonte: Próprio autor, 2017.

FIGURA 2. Viga fletida com cedência de apoio

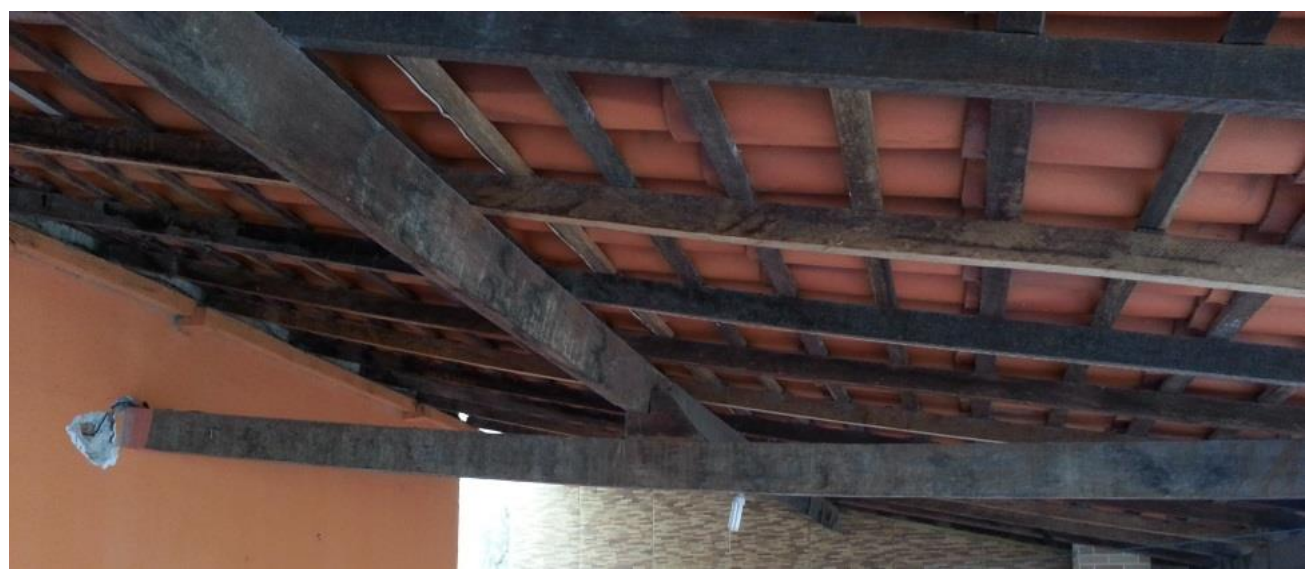

Fonte: Próprio autor, 2017 


\section{CONQGEESOOCIENCIAESOCIEDADE

ANAIS CBCS 2019 | 3 a 5 de outubro de 2019 | Centro Universitário Santo Agostinho - Teresina - PI

Uma forma de se determinar o quanto esta viga da Figura 2 do telhado do estudo de caso deformou e se atende às prescrições da norma é através da fórmula a seguir. É importante citar que há a possibilidade que aja um cisalhamento na viga e por isso a mesma está fletida já que é um esforço na direção longitudinal e causado por uma força cortante atuante que no caso seria o próprio peso da trama que descarrega na viga. A análise dos casos mais simples é feita apenas em relação ao estado limite de utilização que define até quanto pode haver deformações. E em relação a estas, os deslocamentos finais, que apresentam instantâneos somados com os de fluência, tem que ser menor que os valores limites para que não aja danos nos elementos que estão ligados à viga levando em consideração o desconforto do usuário. Assim, a condição para que isso aconteça é que a flecha em função do seu carregamento ( $f$ ef) e o valor que a norma permite para vigas de madeira de acordo com os casos (flim) é dado pela seguinte equação para questão de segurança (NBR 7190:1997).

$$
\text { fef } \leq \text { flim }
$$

A flecha é calculada baseando-se na seguinte fórmula.

Onde q: carregamento;

$$
\text { Flech } a=f=\frac{5 \times q \times L^{4}}{384 \times E \times I}
$$

L: vão;

E: módulo de elasticidade;

I: momento de inércia.

FIGURA 3. Telhas mal encaixadas

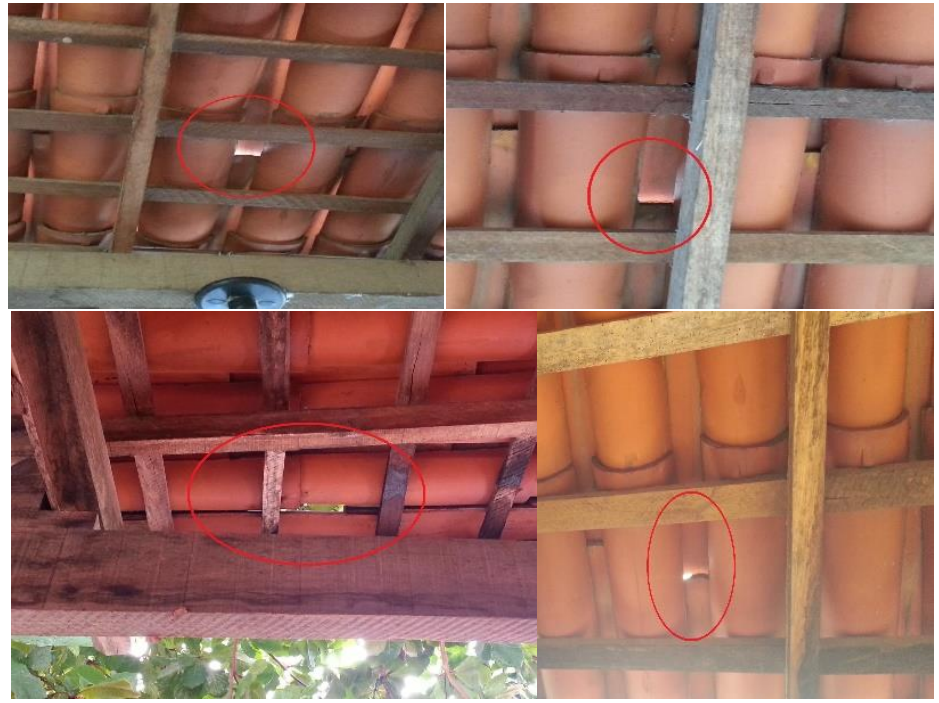

Fonte: Próprio autor, 2017. 


\section{CONQGEESOOCIENCIAESOCIEDADE Inovação, Diversidadie e Sustentahilitidade}

ANAIS CBCS 2019 | 3 a 5 de outubro de 2019 | Centro Universitário Santo Agostinho - Teresina - PI

Tendo como base as informações acima, a análise feita nas fotos registradas e através da associação com o referencial teórico, pôde-se constatar claramente que há a hipótese da maioria das patologias serem causadas por agentes físicos (abióticos) de origem estrutural e outras patologias causadas por agente biótico devido a algumas manchas de umidade (infiltração) identificada pela variação na coloração da madeira como pode ser visto na Figura 4. Em seguida apresentam-se as conclusões alcançadas.

FIGURA 4. Manchas de umidade

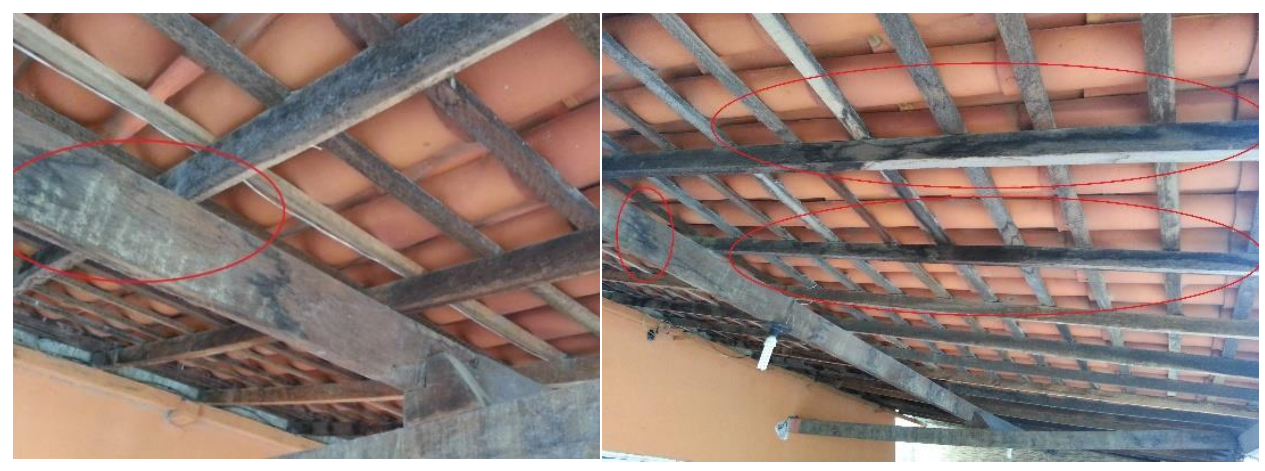

Fonte: Próprio autor, 2017.

Manifestação das patologias: Flechas observáveis com deformações e deslocamentos visíveis (ver Figura 2); Instabilidade lateral (ver Figura 2); Cedência do apoio; Sobrecarga; Manchas com variação de coloração (ver Figura 4).

Causas: A falta de manutenção frequente; Seção insuficiente para uso; Alterações intencionais; Resultado de muitos anos de serviço; A fluência (aumento de flechas); Falhas de utilização, de análise e concepção; Deficiência de nivelamento dos elementos (paredes), onde são feitas as entradas das vigas; Erro nas ligações entre os elementos estruturais; Infiltrações geradas por goteiras pela a má colocação das telhas.

Decisão de intervenção: Para remover as manchas na estrutura de madeira, sugere-se, após a limpeza da área, a utilização de um produto Clareant (sal azedo) para remover as manchas e qualquer outro resíduo por pincelamento. E é preciso reencaixar as telhas apoiadas nas ripas onde podem ficar amarradas entre si para evirar deslocamentos e, assim, prevenir goteiras. Substituir 


\section{CONGQEESSOCIENCIAESOCIEDADE

ANAIS CBCS 2019 | 3 a 5 de outubro de 2019 | Centro Universitário Santo Agostinho - Teresina - PI

integral ou parcialmente a madeira por soluções modernas ao nível de concepção, materiais e técnicas de ligação usada, mantendo algumas soluções originais (reabilitação com substituição integral ou parcial da solução). Sugere-se que a reabilitação, ou reforços, seja feita com cobre juntas externas, com a técnica de aumento da geometria do elemento, onde envolve a adição de material que pode ser de madeira, com as mesmas características e dimensões do original, ou chapas metálicas unidas com parafusos, para enrijecer os elementos estruturais já existentes. Assim, aumenta-se a seção efetiva e, consequentemente, a inércia juntamente com a capacidade de carregamento, diminuindo sensivelmente as deformações excessivas e as flechas observáveis (RITTER; MORRELL, 1990). As reabilitações com cobre juntas podem ser por emendas com cobre juntas pontuais em trechos pontuais específicos [ver Figura 5 - A)], e com aumento da inércia com adição de cobre juntas paralelas, ver Figura 5 - B).

FIGURA 5. A): Emendas ou reforço com cobre juntas externas de madeira parafusadas onde restaura-se a transferência de carregamento em um ponto de ruptura; B): Emendas com cobre juntas com chapas metálicas externas parafusadas paralelas, está mais associada com o enrijecimento dos elementos onde a capacidade resistente é insuficiente
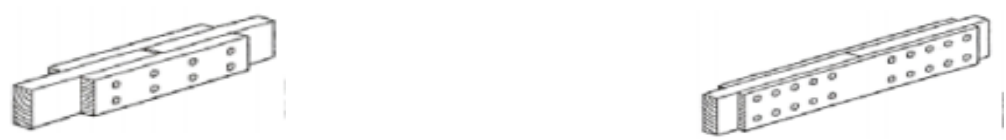

Fonte: UZIELLI, 1995.

\section{CONCLUSÃO}

É importante esclarecer que mesmo com a evolução tecnológica das indústrias de construção adequando-se a métodos qualitativos em seus produtos, as patologias tendem a aparecer, sendo estas condicionadas por erros na execução, no projeto e nas manutenções. Recomendando que, com relação às manutenções, que sejam as preventivas, embora grande parte 


\section{CONGEESSO CIENCIAESOCIEDADE Inovação, Diversidadie e Sustentahilitidade}

ANAIS CBCS 2019 | 3 a 5 de outubro de 2019 | Centro Universitário Santo Agostinho - Teresina - PI

dos casos seja as corretivas. Pois com as preventivas podem-se presumir possíveis falhas e defeitos ao longo da vida útil da estrutura.

Este trabalho adequa-se como sendo uma assessoria para estudos relacionados ao tema, pois os problemas detectados podem ser prevenidos nas etapas construtivas. E com esses problemas viu-se, no estudo de caso, a necessidade de reforços à estrutura de madeira devido às deformações e flechas aparentes, principalmente. Além disso, um planejamento de concepção que deve ser seguido corretamente para que a madeira a ser utilizada venha garantir durabilidade e desempenho em serviço.

\section{REFERÊNCIAS}

ALVIM, R. C.; VELOSO, L. A. C. M.; ALMEIDA, P. A. O.; ALVIM, R. A. A. Metodologia para avaliação da segurança de estruturas do tipo Hauff em coberturas de grande porte de madeira no Brasil. Anais CIMAD 11, Coimbra, 2011.

ARRIAGA, F.; PERAZA, F.; ESTEBAN, M.; BOBADILLA, I.; GARCÍA, F. Intervención en estructuras de madera. Espanha: Editora AITIM, 2002.

ASSOCIAÇÃO BRASILEIRA DE NORMAS TÉCNICAS. NBR 7190: Projeto de estruturas de madeira. Rio de Janeiro, 1997.

BRANCO, F.; BRITO, J.; Flores, I.; GASPAR, F.; SANTOS, S.; PAULO, P.; CAMPOS, J.; Alexandre, J. Diagnóstico e patologia de construções em madeira. Curso de Inspeção e Reabilitação de Construções, Módulo IR2, Instituto Superior Técnico, Lisboa, 2012.

BRITO, L. D.; CALIL JR., C. Evaluation by visual inspection technique of Hauff type timber roof structure at São Carlos Clube Gymnasium in Brazil. LNEC - Laboratório Nacional de Engenharia Civil, Lisboa, 2012.

BRITO, L. D. Patologia em Estruturas de Madeira: Metodologias de Inspeção e Técnicas de Reabilitação. Tese (Doutorado) - Curso de Engenharia de Estruturas, Departamento de Engenharia de Estruturas, São Carlos, 2014. 
ANAIS CBCS 2019 | 3 a 5 de outubro de 2019 | Centro Universitário Santo Agostinho - Teresina - PI

CALIL J. R. Manual de projeto e construção de pontes de madeira. 2006. Disponível em: <http://www.set.eesc.usp.br/ portal/pt/livros/361-manual-de-projeto-e-construcao-de-pontes-demadeira> Acesso em: 26 dez. 2017.

CRUZ, H. Patologia, avaliação e conservação de estruturas de madeira. II Curso Livre Internacional de Patrimônio. Associação Portuguesa dos Municípios com centro histórico. Forum UNESCO Portugal. Santarém, 2001.

CRUZ, H. Patologia em estruturas de Madeira: Ação de Agentes Biológicos. 2016. Disponível em: <http://www.set.eesc.usp.br/static/media/producao/2014DO_LeandroDussarratBrito.pdf> Acesso em: 26 dez. 2017.

DRIEMEYER, R. A. Contribuições para a conservação do patrimônio histórico edificado em madeira da cidade de Antônio Prado/RS. Dissertação (Mestrado) Pós-graduação Engenharia Civil, Centro Tecnológico, Universidade Federal de Santa Catarina, Florianópolis, 2009.

ETTEM, C. J.; ROBINSON, G. C. The Repair of Structural Timber. International Timber Engineering Conference London, London, 1991.

MACHADO, J. S.; DIAS, A.; CRUZ, H.; CUSTÓDIO, J.; PALMA, P. Avaliação, Conservação e Reforço de Estruturas de Madeira. Portugal: Editora Verlag Dashöfer, 2009.

MENDES, A. de S.; ALVES, M. V. da S. A degradação da madeira se sua preservação. Brasília: Ministério da Agricultura, 1988.

RITTER, M. A.; MORRELL, J. J. Timber Bridges: Design, Construction, Inspection and Maintenance. United States Department of Agriculture, USDA, Forest Service, United States, 1990.

COSTA, L. S. Tipificação de soluções de reabilitação de pavimentos estruturais em madeira em edifícios antigos. Dissertação (Mestrado) Faculdade de Engenharia, Universidade do Porto, Portugal, 2009.

SOUZA, V. C. M.; RIPPER, T. Patologia, recuperação e reforço de estruturas de concreto. São Paulo: Editora Pini, 1998.

UZIELLI, L. Restoring timber structures - Repair and strengthening. Università degli Studi di Firenze, The Netherlands, 1995. 